\title{
De hond als kankermodel in de zoektocht naar nieuwe therapeutische alternatieven
}

\author{
1,2*E. Abma, ${ }^{2,3^{*}}$ L. Cicchelero, ${ }^{1,2}$ H. de Rooster, ${ }^{1,2}$ S. Daminet, ${ }^{2,3}$ N.N. Sanders \\ ${ }^{1}$ Vakgroep Geneeskunde en Klinische Biologie van de Kleine Huisdieren, \\ Faculteit Diergeneeskunde, Universiteit Gent, Salisburylaan 133, B-9820 Merelbeke, België \\ ${ }^{2}$ Kankeronderzoeksinstituut CRIG, Gent, België \\ ${ }^{3}$ Vakgroep Voeding, Genetica en Ethologie, \\ Faculteit Diergeneeskunde, Universiteit Gent, Salisburylaan 133, B-9820 Merelbeke, België \\ *De bijdrage van beide auteurs is gelijkwaardig \\ hilde.derooster@ugent.be
}

\section{AMENVATTING}

In het kankeronderzoek wordt het knaagdierkankermodel beschouwd als de standaard. De translatie van onderzoeksresultaten van knaagdier naar mens is echter verre van optimaal en het wordt dan ook aanbevolen om de werkzaamheid van nieuwe kankergeneesmiddelen te bevestigen bij hogere diersoorten vooraleer humane studies worden gestart. Honden met spontane kanker zijn de perfecte kandidaten. De histologische, biologische en genetische achtergrond van kanker is beter vergelijkbaar tussen honden en mensen dan tussen knaagdieren en mensen. Tevens zijn de tumorontwikkeling en de interactie tussen de tumor, de gastheer en de micro-omgeving van de tumor analoog aan die bij de mens. De diagnostische en behandelingsmogelijkheden voor de hond zijn overeenkomstig met die voor de mens, terwijl de progressie van kanker bij honden snel genoeg is om binnen een aanvaardbare termijn resultaten te bekomen. Tenslotte is het reglementair gezien makkelijker om honden op te nemen in klinische onderzoeken dan humane patiënten, wat uitgebreide mogelijkheden voor onderzoek verschaft. De hond zelf heeft bovendien ook baat bij deelname aan klinische studies omdat deze een bijkomende kans op genezing kunnen bieden.

\section{ABSTRACT}

In cancer research, rodent cancer models are a standard research tool. However, translation of cancer research data from rodent to man is far from optimal. Hence, it is recommended that the efficacy of novel cancer drugs is confirmed in higher animal species before human trials are initiated. Pet dogs with spontaneous cancer are the perfect candidates in every respect. Dogs share a similar histologic, biologic and genetic cancer background significantly closer than the relationship between rodent and man. Furthermore, the development and interaction between tumor, host and tumor microenvironment is comparable to those in humans. There are corresponding diagnostic and treatment options available for dogs and humans, while the progression of cancer in dogs is fast enough to obtain results within a reasonable period of time. Lastly, pet dogs have a broader access to clinical trials than humans, enabling extensive research opportunities. Moreover, the dog also benefits from participation in clinical studies, since these studies offer an additional treatment option, and hence an additional chance of being cured.

\section{KNAAGDIERKANKERMODELLEN}

Knaagdierkankermodellen worden in kankeronderzoek beschouwd als het standaard model en bieden een welbekende basis voor het testen van de toxiciteit, de potentie en de therapeutische doeltreffendheid van nieuwe kankertherapeutica (Riccardo et al., 2015). Knaagdieren zijn populair als kankermodel vanwege een brede waaier aan voordelen. De meeste onder- zoeksmethoden zijn uitermate toegespitst op knaagdieren. De overgrote meerderheid van de beschikbare antistoffen zijn gevalideerd voor gebruik bij knaagdieren. Daarnaast bieden inteeltlijnen een zeer goede standaardisatie en is er de mogelijkheid om tumoren te laten ontwikkelen uit kankercellen afkomstig van dieren van dezelfde lijn. Daarenboven zijn knaagdieren makkelijk en goedkoop te huisvesten en onderhouden. Maar de translatie van kankeronderzoek van 
knaagdier naar mens blijkt vaak verre van optimaal. Slechts een derde van de meest succesvolle knaagdieronderzoeken wordt effectief opgenomen in humane klinische studies (Hackam en Redelmeier, 2006; Mak et al., 2014) en ondanks succesvolle preklinische proeven in knaagdiermodellen faalt $85 \%$ van deze proeven in daaropvolgende humane klinische studies. Het gros van deze falende proeven beslaat het onderzoek naar kankertherapeutica (Arrowsmith, 2011).

Er wordt verondersteld dat dergelijke proeven falen bij humane patiënten omwille van een grotere concentratie aan circulerende immunosuppressieve cytokinen en de aanwezigheid van verscheidene immunosuppressieve checkpoints bij de mens die mogelijk minder aanwezig zijn bij knaagdieren (Yaddanapudi et al., 2013). Daarnaast is er een verschil in werking van zowel de aangeboren als verworven immuniteit tussen mens en knaagdier. Dit omvat verschillen in leukocyten, Toll-like-receptoren, natural killer-cel, inhibitorische receptoren, Fc-receptoren, immunoglobulinen, componenten van de B-cel- en T-cel- signaalcascade, $\gamma \mathrm{d}$ T-cellen, cytokinen en cytokine receptoren, Th1/Th2-differentiatie, de antigen-presenterende functie van endotheliale cellen en tot slot chemokinen en de expressie van chemokinereceptoren (Mestas en Hughes, 2004). Een ander zeer belangrijk feit is dat de tumoren bij knaagdiermodellen heel vaak artificieel worden geïnduceerd, ofwel door middel van injectie met chemicaliën, ofwel door middel van inoculatie met gekweekte kankercellen. Dit verschilt sterk van het ontstaan van een spontane kanker, dat een langzaam en ingewikkeld proces is. Daarnaast zijn de inteelt-knaagdierlijnen niet volledig immunocompetent, waardoor deze modellen de complexiteit van spontane kankers niet kunnen benaderen. Door deze inherente verschillen in kankerontwikkeling tussen knaagdierkankermodellen en humane patiënten kunnen knaagdierkankermodellen het extreem complexe proces van humane carcinogenese niet perfect weerspiegelen (Mak et al., 2014). Als gevolg hiervan hebben experimentele testen bij knaagdierkankermodellen een zeer lage voorspellende waarde wat betreft de doeltreffendheid van antitumorale behandelingen bij mensen (Pang en Argyle, 2009; Denies en Sanders, 2012; Pinho et al., 2012). Dit leidt tot dure en weinig efficiënte fase I-onderzoeken bij mensen, wat de vraag doet rijzen naar een alternatief en intermediair dierlijk model voor humane oncologische patiënten. $\mathrm{Na}$ een initiële evaluatie met positieve resultaten bij knaagdiermodellen wordt dan ook aangeraden om therapeutische agentia verder te evalueren bij hogere diersoorten (Riccardo et al., 2015).

\section{DE HOND ALS KANKERMODEL}

Sinds 1976 worden verscheidene klinische proeven uitgevoerd op honden met spontane kanker waarbij de resultaten een meerwaarde hebben geboden voor de informatie die reeds vergaard werd uit de meer traditionele onderzoeksvormen, zoals knaagdiermodellen en humane klinische proeven (Benjamini et al., 1976). Klinische proeven bij honden hebben onderzoekers in staat gesteld om informatie te bekomen die tot dan toe moeilijk of onmogelijk te vergaren was bij knaagdieren of humane patiënten (Paoloni en Khanna, 2008).

Meer en meer wordt duidelijk dat er biologische, praktische en reglementaire argumenten zijn voor het gebruik van honden met spontane kanker als een intermediair model in humaan kankeronderzoek.

\section{Biologische argumenten}

Vanuit biologisch standpunt bieden klinische proeven met honden verscheidene voordelen voor het humane kankeronderzoek. Naast het feit dat tumoren bij honden ontstaan in aanwezigheid van een werkend immuunsysteem, is ook de biologische, histologische en genetische achtergrond van kanker veel beter vergelijkbaar tussen honden en mensen dan tussen knaagdieren en mensen (Lindblad-Toh et al., 2005).

Aangezien kanker bij honden spontaan ontstaat, zijn de tumorontwikkeling en de interactie tussen de tumor, de gastheer en de micro-omgeving van de tumor vergelijkbaar met deze bij mensen (Paoloni en Khanna, 2008). Het spectrum van kanker bij de hond is even divers als bij de mens en de initiatie en progressie ervan worden beïnvloed door gelijkaardige factoren, waaronder leeftijd, geslacht, voortplantingsstatus, voeding en omgevingsfactoren (Hayes en Fraumeni, 1977; Mukaratirwa et al., 2005; Olson 2007). Daarenboven resulteert de intratumorale (celtot-cel) heterogeniciteit van deze kankers in dezelfde dodelijke eigenschappen als die van humane kankers, waaronder verworven therapieresistentie, herval en metastasering (Paoloni en Khanna, 2008).

Bij verschillende tumoren werd aangetoond dat er overtuigende histologische gelijkenissen bestaan tussen kankers bij hond en mens. Histologische analogie werd gevonden in melanomen, non-hodgkinlymfomen, leukemie, osteosarcomen, wekedelensarcomen en in prostaat-, mamma-, long-, hoofd-, nek- en blaascarcinomen (Paoloni en Khanna, 2008).

Daarnaast zijn de genetische moleculaire veranderingen die kanker aansturen vrijwel identiek bij honden en mensen (Lindblad-Toh et al., 2005; Paoloni en Khanna, 2008). Dit werd ondertussen aangetoond bij lymfomen, osteosarcomen, melanomen, gliomen en wekedelensarcomen (Vail en McEwen, 2000; Paoloni en Khanna, 2008; Rankin et al., 2012) maar is allicht ook voor de meeste andere kankertypes het geval. Alhoewel er geargumenteerd wordt dat hondenpopulaties meer inteelt bevatten dan mensenpopulaties, werd er reeds aangetoond dat de genetische diversiteit voor een bepaald tumortype in beide populaties gelijkaardig zijn (Pang en Argyle, 2009).

Deze overeenkomsten hebben als gevolg dat de reactie op therapie bij de hond gelijkaardig is aan 
de reactie op therapie bij de mens en aldus een zeer hoge voorspellende waarde heeft (Paoloni en Khanna, 2008).

\section{Praktische argumenten}

Vanuit praktisch standpunt zijn gelijkaardige diagnostische en behandelingsmethoden mogelijk voor honden en mensen. Chirurgische interventies, medische beeldvorming en staalname van weefsels en/of bloed bij honden zijn vergelijkbaar met die bij humane patiënten (Vail en McEwen, 2000; Pinho et al., 2012). Het huidige wetenschappelijke klimaat is gunstig voor klinisch onderzoek op honden vanwege de steeds toenemende diersoortspecifieke onderzoeksmethoden (Vail en McEwen, 2000; Pinho et al., 2012; Khanna et al., 2009) en toename van diergeneeskundige infrastructuren die voldoen aan de strenge normen voor 'good clinical practice' (Khanna et al., 2009).

Vergeleken met onderzoek bij humane patiënten is klinisch onderzoek bij honden zeer tijdbesparend. Een aantal kankertypes, zoals osteosarcomen en hersentumoren, komt vaker voor bij honden dan bij mensen; dit leidt tot een hoger aantal patiënten die gerekruteerd kunnen worden voor klinisch onderzoek en aldus tot het sneller bekomen van resultaten. Daarenboven is de progressie van kanker bij honden enerzijds traag genoeg om reactie op de therapie betrouwbaar te kunnen vergelijken en anderzijds snel genoeg om resultaten te bekomen binnen een aanvaardbare termijn (Vail en McEwen, 2000 ; Pinho et al., 2012). De gouden standaard voor de evaluatie van therapeutisch kankeronderzoek is de "overall survival", en het relatief korte verloop van kanker bij honden laat een doeltreffende en tijdige beoordeling toe van nieuwe kankertherapieën (Paoloni en Khanna, 2008 ; Olin et al., 2014). Terwijl de beoordeling van het ziektevrijinterval of de overlevingsduur binnen humane onderzoeken vaak meerdere, soms tot tientallen jaren beslaat, neemt het verkrijgen van dezelfde informatie bij klinisch onderzoek op honden veel minder tijd in beslag, in een aantal gevallen slechts enkele maanden (Gabai et al., 2014).

Al deze factoren maken het mogelijk om klinische proeven met voldoende statistische 'power' te kunnen ontwerpen (Vail en McEwen, 2000 ; Rankin et al., 2012). Nog een niet onbelangrijk voordeel van klinische proeven op honden is de lagere kostprijs dan van humane klinische proeven (Vail en McEwen, 2000 ; Olin et al., 2014).

Niettemin blijven de voordelen van het klinisch onderzoek bij honden niet enkel beperkt tot het vormen van een fundering voor humaan kankeronderzoek. Vooralsnog zijn de behandelingsmethoden in de veterinaire oncologie eerder beperkt. Klinische studies kunnen een extra kans op genezing bieden bij honden die uitbehandeld zijn of bij honden waarvan de eigenaars kostenbeperkt zijn. Veel eigenaars van honden met kanker willen de beste optie voor hun huisdier en zijn bereid om deel te nemen aan klinische onderzoeken. Hun bijdrage in het voordeel van de veterinaire en humane medische wetenschappen wordt over het algemeen als zeer positief beschouwd. Zelfs indien de experimentele behandeling onvoldoende curatief effect teweegbrengt, appreciëren de eigenaars de grondige opvolging en begeleiding van hun huisdier tijdens een klinische studie. Hierdoor kunnen de onderzoekers vaak rekenen op uitgesproken therapietrouw, het terugkeren voor regelmatige opvolging, de toelating tot bioptname en zelfs autopsie (Vail en McEwen, 2000).

\section{Reglementair}

Vanuit reglementair standpunt is het makkelijker om honden te laten deelnemen aan klinische studies dan humane patiënten. Bij humane patiënten wordt de toegang tot klinische onderzoeken enkel toegestaan in refractaire gevallen. In de diergeneeskunde is dit niet het geval. Elke patiënt mag deelnemen wanneer er door de eigenaar een voorgelichte toestemming wordt ondertekend en er door de onderzoekers toestemming van de ethische en de deontologische commissie werd bekomen. Dit laat toe om nieuwe therapeutische mogelijkheden te evalueren in de vroegste fase van kanker maar ook in gevallen van minimaal overblijvende ziekte, bijvoorbeeld na chirurgie of chemotherapie (Vail en McEwen, 2000). Translationeel onderzoek kan gefaciliteerd worden door een goede samenwerking tussen diergeneeskunde en humane geneeskunde en aldus kunnen dure fase I-onderzoeken bij humane patiënten geoptimaliseerd of zelfs vermeden worden.

\section{Ervaring tot nu toe}

Een goede wisselwerking tussen veterinaire en humane onderzoeksinitiatieven heeft al geleid tot de ontwikkeling van een vaccin met een adenovirale vector gericht tegen dendritische cellen (Thacker et al., 2009), nieuwe lidmaat-sparende technieken bij patiënten met osteosarcoom (Paoloni en Khanna, 2008), de inhalatie van cytokinen bij de behandeling van humane patiënten met pulmonaire metastasen (Paoloni en Khanna, 2008) en een DNA-vaccin voor melanomen bij honden (Oncept ${ }^{\circledR}$, Merial, VS), waarvan de doeltreffendheid en veiligheid geleid heeft tot verdergezet klinisch onderzoek bij humane patiënten met melanomen (Gabai et al., 2014).

Natuurlijk is klinisch onderzoek op honden met kanker niet enkel bevorderlijk voor de ontwikkeling van nieuwe kankerbehandelingen, het draagt ook bij tot het onderzoek van milieurisicofactoren, kankerbiologie en -progressie en de identificatie van kankergeassocieerde genen (Paoloni en Khanna, 2008).

Zowel op biologisch, praktisch en reglementair vlak is de hond met spontane kanker een ideaal intermediair diermodel voor humane oncologische patiënten. 


\section{REFERENTIES}

Arrowsmith J. (2011). Trial watch: phase III and submission failures: 2007-2010. Nature Reviews Drug Discovery 10,87 .

Benjamini E, Theilen GH, Torten M, Fong S, Crow S, Henness AM. (1976). Tumor vaccines for immunotherapy of canine lymphosarcoma. Annals of the New York Academy of Sciences 277, 305-312.

Denies S, Sanders NN. (2012). Recent progress in canine tumor vaccination: potential applications for human tumor vaccines. Expert Review of Vaccines 11, 1375-1386.

Gabai V, Venanzi FM, Bagashova E, Rud O, Mariotti F, Vullo C, Catone G, Sherman MY, Concetti A, Chursov A, Latanova A, Shcherbinina V, Shifrin V, Shneider A. (2014). Pilot study of p62 DNA vaccine in dogs with mammary tumors. Oncotarget 5, 12803-12810.

Hackam DG, Redelmeier DA. (2006). Translation of research evidence from animals to humans. Journal of the American Medical Association 296, 1731-1732.

Hayes HM, Jr., Fraumeni JF, Jr. (1977). Epidemiological features of canine renal neoplasms. Cancer Research 37, 2553-2556.

Khanna C, London C, Vail D, Mazcko C, Hirschfeld S. (2009). Guiding the optimal translation of new cancer treatments from canine to human cancer patients. Clinical cancer research: an official journal of the American Association for Cancer Research 15, 5671-5677.

Lindblad-Toh K, Wade CM, Mikkelsen TS, Karlsson EK, Jaffe DB, Kamal M, Clamp M, Chang JL, Kulbokas EJ, 3rd, Zody MC. (2005). Genome sequence, comparative analysis and haplotype structure of the domestic dog. $\mathrm{Na}$ ture 438, 803-819.

Mak IW, Evaniew N, Ghert M. (2014). Lost in translation: animal models and clinical trials in cancer treatment. American Journal of Translational Research 6, 114-118.

Mestas J, Hughes CC. (2004). Of mice and not men: differences between mouse and human immunology. Journal of Immunology 172, 2731-2738.

Mukaratirwa S, Chipunza J, Chitanga S, Chimonyo M, Bhebhe E. (2005). Canine cutaneous neoplasms: prevalence and influence of age, sex and site on the presence and potential malignancy of cutaneous neoplasms in dogs from Zimbabwe. Journal of the South African Veterinary Association 76, 59-62.

Olin MR, Pluhar GE, Andersen BM, Shaver R, Waldron NN, Moertel CL. (2014). Victory and defeat in the induction of a therapeutic response through vaccine therapy for human and canine brain tumors: a review of the state of the art. Critical Reviews in Immunology 34, 399-432.

Olson PN. Using the canine genome to cure cancer and other diseases. Theriogenology 68, 378-381.

Pang LY, Argyle DJ. (2009). Using naturally occurring tumours in dogs and cats to study telomerase and cancer stem cell biology. Biochimica et biophysica acta 1792, 380-391.

Paoloni M, Khanna C. (2008). Translation of new cancer treatments from pet dogs to humans. Nature Reviews Cancer 8, 147-156.

Pinho SS, Carvalho S, Cabral J, Reis CA, Gartner F. (2012). Canine tumors: a spontaneous animal model of human carcinogenesis. Translational research: the Journal of Laboratory and Clinical Medicine 159, 165-172.

Rankin KS, Starkey M, Lunec J, Gerrand CH, Murphy S, Biswas S. (2012). Of dogs and men: comparative biology as a tool for the discovery of novel biomarkers and drug development targets in osteosarcoma. Pediatric Blood \& Cancer 58, 327-333.

Riccardo F, Aurisicchio L, Impellizeri JA, Cavallo F. The importance of comparative oncology in translational medicine. Cancer Immunology, Immunotherapy 64, 137148.

Thacker EE, Nakayama M, Smith BF, Bird RC, Muminova Z, Strong TV, Timares L, Korokhov N, O'Neill AM, de Gruijl TD, Glasglow JN, Tani K, Curiel DT. (2009). A genetically engineered adenovirus vector targeted to CD40 mediates transduction of canine dendritic cells and promotes antigen-specific immune responses in vivo. Vaccine 27, 7116-7124.

Vail DM, MacEwen EG. (2000). Spontaneously occurring tumors of companion animals as models for human cancer. Cancer Investigation 18, 781-792.

Yaddanapudi K, Mitchell RA, Eaton JW. (2013). Cancer vaccines: Looking to the future. Oncoimmunology 2, e23403. 